\title{
Composite colloidal gels made of bisphosphonate- functionalized gelatin and bioactive glass particles for regeneration of osteoporotic bone defects
}

\author{
Citation for published version (APA): \\ Diba, M., Camargo, W. A., Brindisi, M., Farbod, K., Klymov, A., Schmidt, S., Harrington, M. J., Draghi, L., \\ Boccaccini, A. R., Jansen, J. A., van den Beucken, J. J. J. P., \& Leeuwenburgh, S. C. G. (2017). Composite \\ colloidal gels made of bisphosphonate-functionalized gelatin and bioactive glass particles for regeneration of \\ osteoporotic bone defects. Advanced Functional Materials, 27(45), [1703438]. \\ https://doi.org/10.1002/adfm.201703438
}

\section{Document license: \\ TAVERNE}

DOI:

10.1002/adfm.201703438

Document status and date:

Published: 01/12/2017

\section{Document Version:}

Publisher's PDF, also known as Version of Record (includes final page, issue and volume numbers)

\section{Please check the document version of this publication:}

- A submitted manuscript is the version of the article upon submission and before peer-review. There can be important differences between the submitted version and the official published version of record. People interested in the research are advised to contact the author for the final version of the publication, or visit the DOI to the publisher's website.

- The final author version and the galley proof are versions of the publication after peer review.

- The final published version features the final layout of the paper including the volume, issue and page numbers.

Link to publication

\footnotetext{
General rights

- You may freely distribute the URL identifying the publication in the public portal. follow below link for the End User Agreement:

www.tue.nl/taverne

\section{Take down policy}

If you believe that this document breaches copyright please contact us at:

openaccess@tue.nl

providing details and we will investigate your claim.
}

Copyright and moral rights for the publications made accessible in the public portal are retained by the authors and/or other copyright owners and it is a condition of accessing publications that users recognise and abide by the legal requirements associated with these rights.

- Users may download and print one copy of any publication from the public portal for the purpose of private study or research.

- You may not further distribute the material or use it for any profit-making activity or commercial gain

If the publication is distributed under the terms of Article $25 \mathrm{fa}$ of the Dutch Copyright Act, indicated by the "Taverne" license above, please 


\title{
Composite Colloidal Gels Made of Bisphosphonate- Functionalized Gelatin and Bioactive Glass Particles for Regeneration of Osteoporotic Bone Defects
}

\author{
Mani Diba, Winston A. Camargo, Mariateresa Brindisi, Kambiz Farbod, Alexey Klymov, \\ Stephan Schmidt, Matthew J. Harrington, Lorenza Draghi, Aldo R. Boccaccini, \\ John A. Jansen, Jeroen J. J. P. van den Beucken, and Sander C. G. Leeuwenburgh*
}

Injectable composite colloidal gels are developed for regeneration of osteoporotic bone defects through a bottom-up assembly from bisphosphonatefunctionalized gelatin and bioactive glass particles. Upon bisphosphonate functionalization, gelatin nanoparticles show superior adhesion toward bioactive glass particles, resulting in elastic composite gels. By tuning their composition, these composite colloidal gels combine mechanical robustness with self-healing ability. The composite colloidal gels support cell proliferation and differentiation in vitro without requiring any osteogenic supplement. In vivo evaluation of the composite colloidal gels reveals their capacity to support the regeneration of osteoporotic bone defects. Furthermore, the bisphosphonate modification of gelatin induces a therapeutic effect on the peri-implantation region by enhancing the bone density of the osteoporotic bone tissue. Consequently, these composite colloidal gels offer new therapeutic opportunities for treatment of osteoporotic bone defects.

\section{Introduction}

Bone loss and fracture require effective regenerative treatment, particularly when accompanied by a degenerative condition such as osteoporosis. ${ }^{[1]}$ Currently, the use of autologous bone is still the gold standard in clinical practice for treatment of bone defects. ${ }^{[2]}$ However, disadvantages associated with this treatment modality include donor site morbidity and limited availability. These clinical drawbacks have urged the development of alternative strategies for regeneration of bone tissue. ${ }^{[3]}$ Therefore, extensive research efforts have been dedicated to the development of a wide range of bone regenerative materials. ${ }^{[4]}$
Among these materials, organic-inorganic composites are particularly promising by mimicking the chemical composition of bone, while combining mechanical stability with biocompatibility. ${ }^{[5]}$ In addition, the intraoperative handling properties of bone-substituting biomaterials are crucial for their clinical applicability. ${ }^{[6]}$ Hence, injectable composite biomaterials have recently gained interest for applications in bone regeneration. ${ }^{[6,7]}$ Colloidal gels are particularly promising injectable biomaterials. ${ }^{[8]}$ These gels are solely composed of colloidal particles. Various types of particles can be used as colloidal building blocks, which can be loaded or functionalized with different types of drugs or biomolecules. ${ }^{[9]}$ By utilizing reversible, noncovalent interparticle bonds, selfhealing colloidal gels can be prepared that recover their mechanical properties after destructive shearing upon extrusion through needles. ${ }^{[8 a]}$ Furthermore, the dynamic and adaptive nature of colloidal gel networks can provide an excellent microenvironment for tissue ingrowth and cellular activity, ${ }^{\left[{ }^{8 a}\right]}$ potentially leading to improved bone regeneration.

We have recently shown ${ }^{[8 a-c, 9 b, c, 10]}$ that gelatin-based colloidal gels are promising materials for applications in bone regeneration. Nevertheless, colloidal gels composed of only soft organic particles are mechanically weak and lack sufficient bioactivity. ${ }^{[8 c, d]}$ The performance of these purely organic colloidal systems was enhanced previously by (i) modification of organic particles with functionally and biologically
M. Diba, W. A. Camargo, M. Brindisi, Dr. K. Farbod, Dr. A. Klymov,

Prof. J. A. Jansen, Dr. J. J. J. P. van den Beucken,

Dr. S. C. G. Leeuwenburgh

Department of Biomaterials

Radboud University Medical Center

6525 EX Nijmegen, The Netherlands

E-mail: sander.leeuwenburgh@radboudumc.nl

M. Brindisi, Dr. L. Draghi

Chemistry, Materials and Chemical Engineering Department "G. Natta," Politecnico di Milano

20133 Milano, Italy

DOI: $10.1002 / \mathrm{adfm} .201703438$
Dr. S. Schmidt

Institute of Organic and Macromolecular Chemistry

Heinrich-Heine-University Düsseldorf

40225 Düsseldorf, Germany

Dr. M. J. Harrington

Department of Biomaterials

Max Planck Institute for Colloids and Interfaces

D-14424 Potsdam, Germany

Prof. A. R. Boccaccini

Institute of Biomaterials

Department of Materials Science and Engineering

University of Erlangen-Nuremberg

91058 Erlangen, Germany 


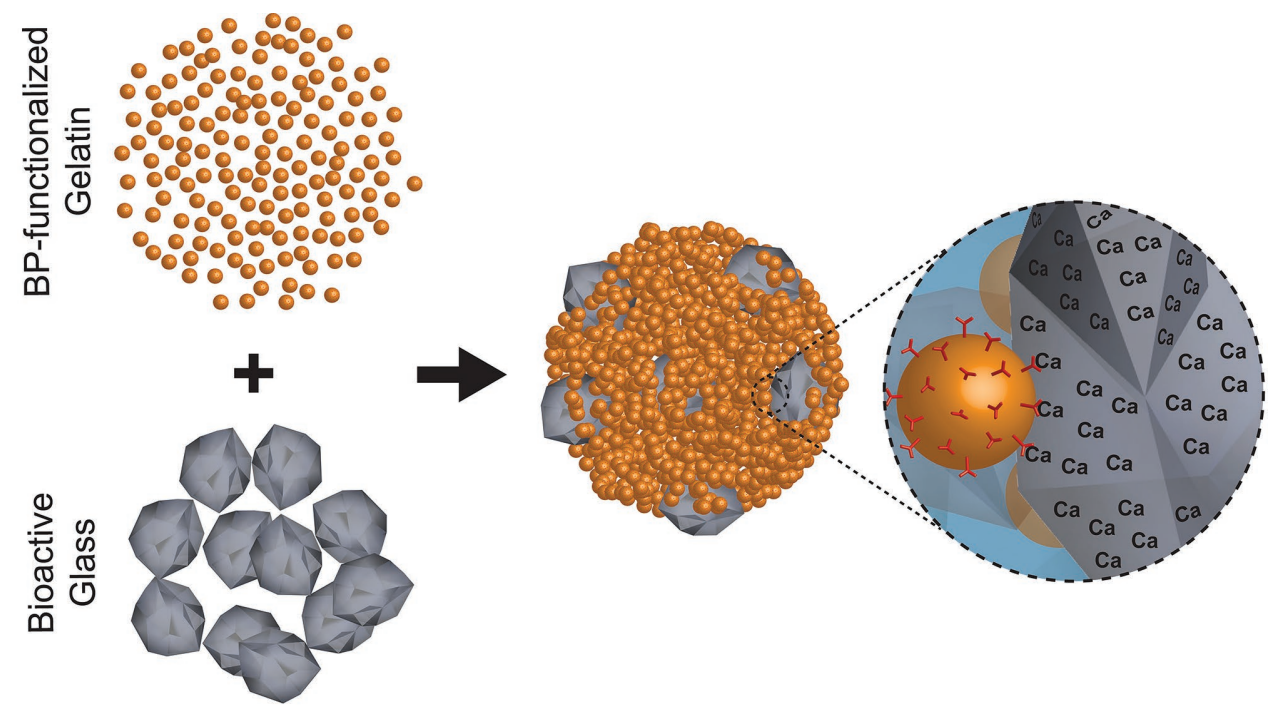

Scheme 1. Schematic illustration of formation of composite colloidal gels composed of bisphosphonate (BP)-functionalized gelatin and bioactive glass particles.

active molecules ${ }^{[9, \mathrm{~d}, 11]}$ or (ii) inclusion of bioactive inorganic particles. ${ }^{[8 a, b]}$ Regarding strategy (i), we have recently demonstrated $^{[11,12]}$ that functionalization of gelatin nanoparticles with bisphosphonate molecules enhances their binding affinity toward calcium-containing minerals, i.e., hydroxyapatite, and induces sustained release of bisphosphonates. Regarding strategy (ii), it was recently shown that the inclusion of inorganic fillers such as bio-inactive silica ${ }^{[8 a]}$ or hydroxyapatite particles $^{[8 b]}$ generates colloidal gel composites with superior mechanical performance. By combining both strategies, we hypothesized that composite colloidal gels can be designed that combine mechanical robustness, bone regenerative capacity, and antiosteoporotic therapeutic efficacy.

Here, we report the development of injectable composite colloidal gels assembled from bisphosphonate-functionalized gelatin and bioactive glass (BG) particles (Scheme 1). Gelatin was used to prepare the organic building blocks due to its widespread availability, ${ }^{[13]}$ availability of adhesive cell recognition sites ${ }^{[14]}$ and ease of functionalization. ${ }^{[11,12]} 45 \mathrm{~S} 5$ BG (Bioglass) particles were used as the inorganic building blocks since this glass type is the most common type of BG due to its strong bioactivity and biodegradability. ${ }^{[15]}$ We functionalized the gelatin particles with calcium-binding bisphosphonate groups not only for their capacity to bind to calcium-containing $\mathrm{BGs}$, ${ }^{[16]}$ but also due to their antiosteoporotic efficacy. ${ }^{[17]}$ We first used a colloidal probe atomic force microscopy (AFM) technique to quantify the effect of the bisphosphonate functionalization of gelatin particles on the interparticle adhesion forces between gelatin and BG particles. We then prepared colloidal gels from gelatin nanoparticles, with or without bisphosphonates, and BG particles and studied the viscoelastic properties of the resulting gels. Next, we assessed the in vitro performance of these composite gels by quantifying the proliferation and differentiation of osteoblastic cells cultured on top of the gels, and also evaluated the apatite-forming ability of these materials in the presence or absence of cells. Finally, we examined the bone regenerative capability of the composite colloidal gels in vivo upon implantation into femoral condyle defects in osteoporotic rats.

\section{Results}

\subsection{Characterization of Colloidal Building Blocks}

Figure 1 shows scanning electron microscopy (SEM) images of BG and gelatin particles in dry state. The glass particles were irregularly shaped, whereas the gelatin nanoparticles were highly spherical. The gelatin and BG particles had average sizes of $210 \pm 64 \mathrm{~nm}$ and $2.0 \pm 1.2 \mu \mathrm{m}$, respectively. While the rigid glass particles hardly swelled in water, the average diameter of gelatin nanoparticles increased up to $\approx 332 \pm 3 \mathrm{~nm}$ (Polydispersity index $(\mathrm{PDI})=0.14 \pm 0.02)$ upon swelling in water as measured by means of dynamic light scattering. Sizes and swelling ratios were similar for nonfunctionalized and bisphosphonate-functionalized gelatin nanoparticles, as reported previously. ${ }^{[1]}$ Elemental analysis based on quantification of phosphorous content in gelatin nanoparticles indicated that functionalized gelatin nanoparticles contained $2.40 \pm 0.01 \mathrm{wt} \%$ of bisphosphonate.

\subsection{Atomic Force Microscopy}

Figure 2A illustrates the AFM setup used in this study for the quantification of interactions between gelatin and BG particles. As shown in Figure 2B, both nonfunctionalized and bisphosphonate-functionalized gelatin nanoparticles formed strong adhesive bonds with BG particles, as indicated by multiple adhesion events upon withdrawal of the cantilever. Figure $2 \mathrm{C}$ shows the quantified adhesion force values measured in MilliQ water and phosphate-buffered saline (PBS) solution. These quantifications revealed that the bisphosphonate functionalization of gelatin nanoparticles enhanced their binding affinity toward 

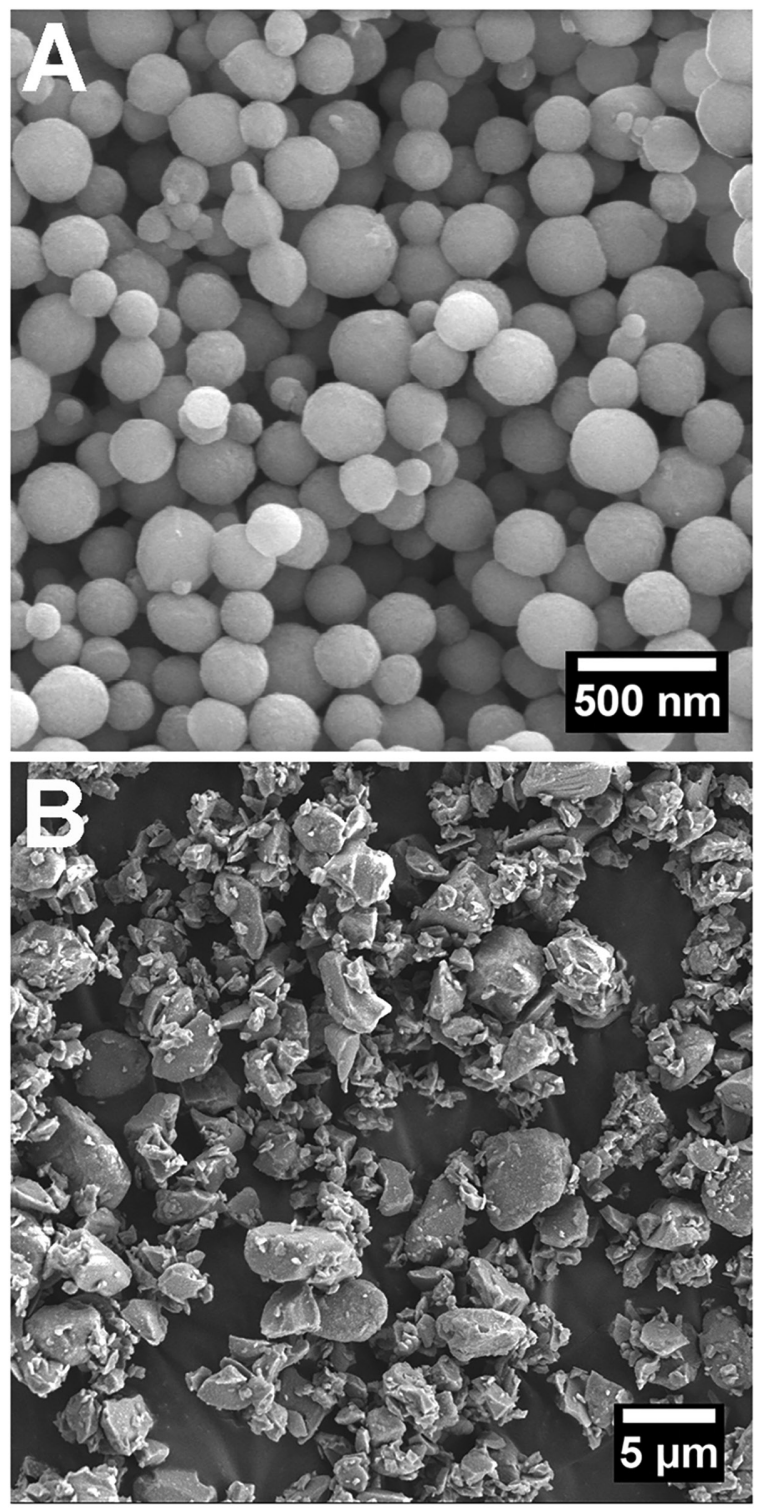

Figure 1. Scanning electron images of A) gelatin and B) bioactive glass particles.
BG about 1.9-fold. When these measurements were performed in PBS solutions, the measured adhesion forces for nonfunctionalized and functionalized gelatin nanoparticles decreased as compared to measurements in MilliQ water. Nevertheless, functionalization of gelatin nanoparticles with bisphosphonate groups resulted in a remarkable 3.6-fold enhancement of the adhesion force in PBS, which was significantly higher as compared to measurements performed in MilliQ water.

\subsection{Viscoelastic Properties of Colloidal Gels}

Figure 3A,B shows the storage modulus ( $\left.G^{\prime}\right)$ and tan(delta) values for colloidal gels composed of nonfunctionalized or bisphosphonate-functionalized gelatin nanoparticles and different amounts of BG particles, at a fixed particle volume fraction of 0.25. Importantly, all the colloidal gel compositions exhibited frequency-independent solid-like behavior (Figure S2, Supporting Information). The incorporation of BG particles into colloidal gelatin gels produced more elastic gels as evidenced by the increase of storage modulus and the decrease of the damping factor tan(delta), which was, however, followed by a substantial increase of $\tan$ (delta) at BG/gelatin ratios of $>1(w / w)$ corresponding to a more viscous behavior for colloidal gels with high inorganic contents. As shown in Figure 3A, pure colloidal gelatin gels composed of bisphosphonate-functionalized gelatin nanoparticles showed significantly lower $G^{\prime}$ and higher tan(delta) values as compared to gels made entirely from nonfunctionalized gelatin nanoparticles. Upon BG incorporation, composite gels containing bisphosphonate-functionalized gelatin nanoparticles exhibited around twofold higher $G^{\prime}$ values at a BG/gelatin ratio of $0.1(\mathrm{w} / \mathrm{w})$, whereas $G^{\prime}$ values were statistically similar for all other BG/gelatin ratios. Furthermore, evaluation of the yield stress indicated that the incorporation of BG particles significantly enhanced the mechanical strength of the colloidal gels. Moreover, similar to the measurements of the storage modulus, the evaluation of the yield stress also revealed that the bisphosphonate functionalization resulted in weaker colloidal gels when only gelatin nanoparticles were used as the colloidal building blocks (Figure S3, Supporting Information).

Since the composite colloidal gels with a BG/gelatin ratio of $0.1(\mathrm{w} / \mathrm{w})$ displayed the most pronounced increase in

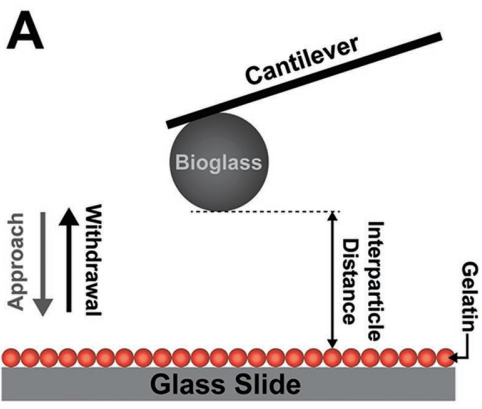

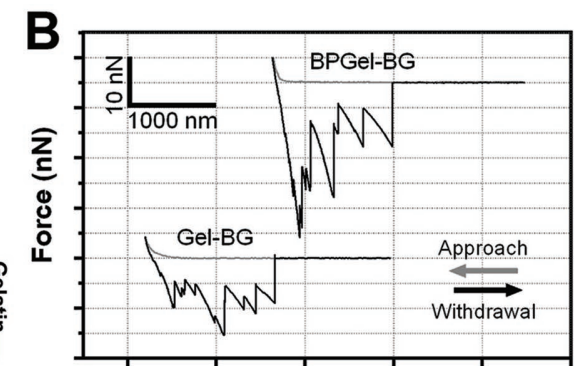

Interparticle distance $(\mathrm{nm})$

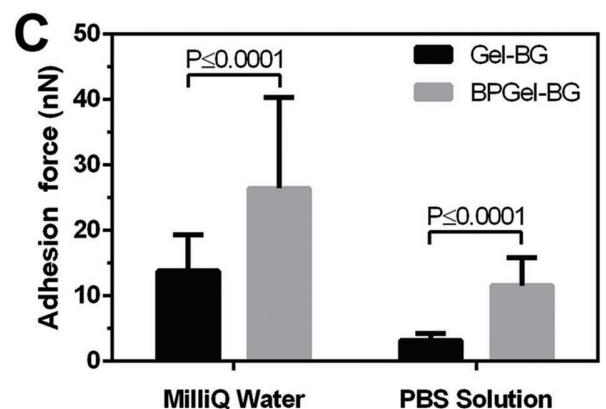

Figure 2. Interparticle adhesion force measurements performed by a colloidal probe AFM technique. A) Schematic illustration of the AFM setup. B) Representative force curves showing interactions of nonfunctionalized (Gel) or bisphosphonate-functionalized gelatin (BPGel) nanoparticles with bioactive glass (BG) particles in MilliQ water. C) Quantified values of the interparticle adhesion force between gelatin and bioactive glass particles in MilliQ water or PBS solution. All values in (C) are presented as average \pm standard deviation for $n=35$ per experimental condition. 

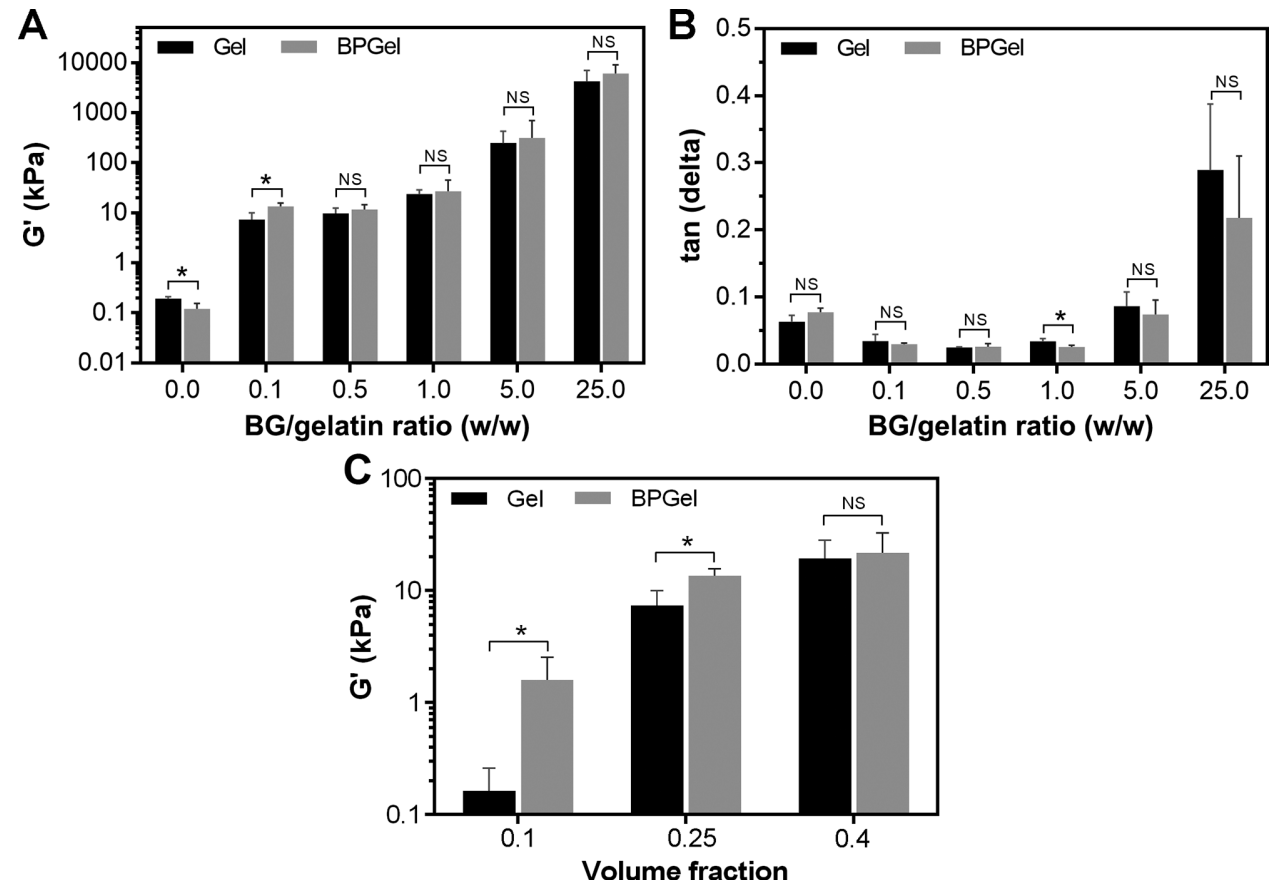

Figure 3. A) Storage modulus (G) and B) tan(delta) of colloidal gels composed of nonfunctionalized (Gel) or bisphosphonate-functionalized (BPGel) gelatin nanoparticles and various contents of bioactive glass. Measurements were performed at a frequency of $1 \mathrm{~Hz}$. All samples in (A) and (B) were prepared with particle volume fraction of 0.25 . C) Storage modulus (G) of composite colloidal gels composed of Gel or BPGel nanoparticles at a BG/ gelatin ratio of $0.1(\mathrm{w} / \mathrm{w})$ and different particle volume fractions. Measurements were performed at a frequency of $1 \mathrm{~Hz}$. All values are presented as average \pm standard deviation for $n=3$ per experimental condition. * and NS indicate $P \leq 0.05$ and not statistically significant, respectively.

storage modulus upon bisphosphonate functionalization, this composition was selected to study the storage modulus of the gels as a function of bisphosphonate functionalization and particle volume fraction. As shown in Figure $3 \mathrm{C}$, the $\mathrm{G}^{\prime}$ value of the gels was strongly enhanced by increasing particle volume fraction. More importantly, storage moduli of gels containing bisphosphonate-functionalized gelatin particles were significantly higher for samples with volume fractions of 0.1 (approximately tenfold increase) and 0.25 (approximately twofold increase), whereas the effect of bisphosphonate functionalization for samples with a volume fraction of 0.4 was not statistically significant.
Figure 4 shows the recovery of colloidal gels after shearinduced gel network destruction. As shown in Figure 4A, composite gels with a low BG content (0.1 BG/gelatin ratio) displayed a liquid-like behavior upon destructive straining up to $1000 \%$ in step (II). Nevertheless, upon removal of this high strain in step (III), these formulations recovered their elasticity almost instantaneously $(<7 \mathrm{~s})$. By increasing the glass content, however, the self-healing ability of the composite gels gradually declined; at a BG/gelatin ratio of $25(\mathrm{w} / \mathrm{w})$, the materials could recover only less than $1 \%$ of their initial $G^{\prime}$ value (Figure $4 \mathrm{~B}$ ). The recovery of the storage modulus of the colloidal gels did not change when the retention time in step (III) was increased up to $30 \mathrm{~min}$.
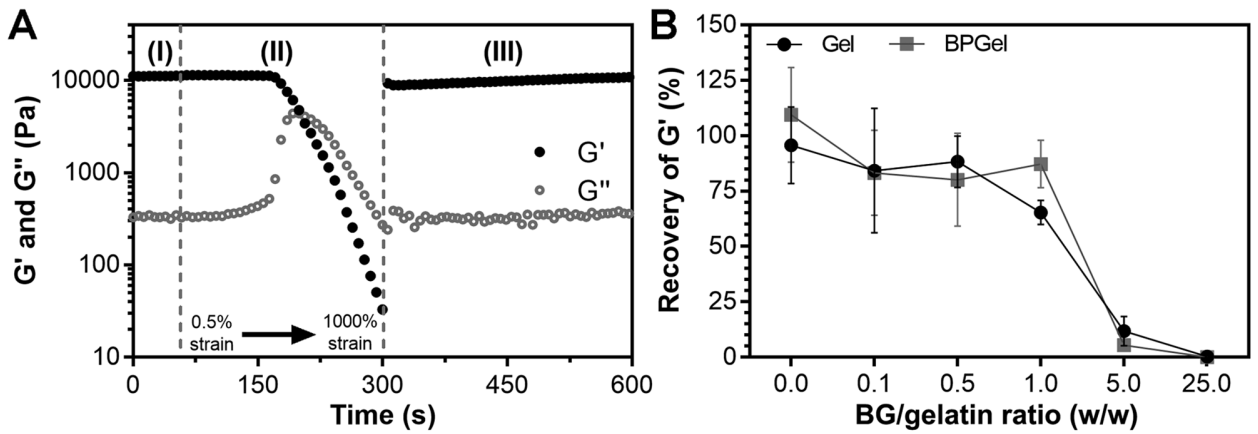

Figure 4. A) Self-healing of a composite colloidal gel (BPGel+BG (0.1)) upon shear-induced failure characterized by rheological tests in three stages: (I) time sweep at $0.5 \%$ strain, (II) network destruction by increasing strain from $0.5 \%$ to $1000 \%$, and (III) recovery at $0.5 \%$ strain. B) Recovery of storage modulus $(G)$ of colloidal gels made with different bioactive glass contents. Measurements were performed at a frequency of $1 \mathrm{~Hz}$. All samples were prepared with a particle volume fraction of 0.25 . All values in (B) are presented as average \pm standard deviation for $n=3$ per experimental condition. 
Table 1. List of colloidal gel samples used for in vitro mineralization experiments. $R$ indicates the $\mathrm{BC} /$ gelatin ratio $(\mathrm{w} / \mathrm{w})$ of the corresponding sample.

\begin{tabular}{lcc}
\hline $\begin{array}{l}\text { Sample } \\
\text { abbreviation }\end{array}$ & Type of gelatin nanoparticles & $\begin{array}{c}\text { BG/gelatin ratio } \\
{[\mathrm{w} / \mathrm{w}]}\end{array}$ \\
\hline Gel & Nonfunctionalized & 0 \\
Gel+BG $(R)$ & Nonfunctionalized & $0.1-0.5$ \\
BPGel & Bisphosphonate-functionalized & 0 \\
BPGel+BG $(R)$ & Bisphosphonate-functionalized & $0.1-0.5$ \\
\hline
\end{tabular}

\subsection{In Vitro Mineralization of Colloidal Gels}

Table 1 lists the compositions of colloidal gels used for in vitro mineralization experiments. Figure 5A,B shows the Fourier transform infrared (FTIR) spectra of freeze-dried colloidal gels after $30 \mathrm{~d}$ of incubation in cell culture medium with or without cells. No remarkable differences were observed between the spectra of samples incubated with or without cells. In these spectra, the sharp peaks at $\approx 570$ and $\approx 600 \mathrm{~cm}^{-1}$ correspond to the $v_{4}$ bending mode of $\mathrm{P}-\mathrm{O}-\mathrm{P}$ bond from the $\mathrm{PO}_{4}{ }^{3-}$ groups of hydroxyapatite. ${ }^{[16,18]}$ Moreover, the peak at $\approx 871 \mathrm{~cm}^{-1}$ is the absorption peak characteristic for $\mathrm{CO}_{3}{ }^{2-}$ group as present in carbonated apatite. ${ }^{[18]}$ Accordingly, no evidence of mineralization was observed for the pure gelatin gels, with or without bisphosphonate functionalization. Similarly, the inclusion of a low amount of BG particles (0.1 BG/gelatin ratio (w/w)) also could not induce apatite formation in bisphosphonate-functionalized gels. Nevertheless, when a higher amount of BG particles (0.5 BG/gelatin ratio $(\mathrm{w} / \mathrm{w})$ ) was combined with the bisphosphonate-functionalized gelatin nanoparticles, the resulting gels promoted apatite formation within their matrix. The assessment of these composite gels at different incubation time points revealed that the formation of apatite minerals in these samples started within the first $10 \mathrm{~d}$ of incubation (Figure S4, Supporting Information).

To obtain a more quantitative insight into the mineralization behavior of the colloidal gels, the dissolution of their BG content and calcium deposition within their matrix were estimated based on their silicon and calcium contents as measured before and after the immersion period. As shown in Figure 5C, when the composite gels contained a low amount of BG particles (0.1 BG/gelatin ratio (w/w)), their BG content was almost completely dissolved during the $30 \mathrm{~d}$ incubation period. On the contrary, the colloidal gels with a high BG content still contained BG particles after the incubation period. Figure 5D shows the estimated amounts (\%) of calcium deposition in the colloidal gels with different compositions. Almost no calcium deposition was observed for the pure gelatin gels without bisphosphonate. Upon bisphosphonate functionalization, a slight increase of calcium deposition was observed for pure gelatin gels. Importantly, the inclusion of BG particles in the composition of gels strongly stimulated calcium deposition within their matrix. The highest level of calcium deposition was, in fact, observed for the composite gels with the highest BG content. However, when comparing these composite gels incubated with or without cells, calcium deposition values were significantly higher for the latter.

\subsection{Cell Proliferation and Osteoblastic Activity}

Figure 6A,B shows the DNA content and alkaline phosphatase (ALP) activity of the cells after 10, 20, and $30 \mathrm{~d}$ of culture on top of various colloidal gels, respectively. At $10 \mathrm{~d}$ of cell culture, DNA content and ALP activity for all experimental groups were similar. Most notably, cells seeded on pure gelatin gels without bisphosphonate showed a strong increase of DNA content until day 20 , followed by a decline at day 30 . However, cells seeded on the composite gels did not show significant variations of DNA content over time.

Concerning the ALP activity of the cells, at $20 \mathrm{~d}$ of cell culture, the bisphosphonate-containing groups showed higher ALP activity levels than the bisphosphonate-free group. Nevertheless, while the cells cultured on the bisphosphonate-free gelatin gels showed increased levels of ALP activity at day 30, the cells cultured on the bisphosphonate-containing gels with high BG content (BPGel+BG(0.5)) showed a peak at day 20, followed by a declined ALP activity at day 30 .

Cytological evaluation of the colloidal gels after $30 \mathrm{~d}$ of cell culture revealed the formation of continuous cell layers on the surface of bisphosphonate-free gelatin gels (Figure 6C). Interestingly, these results also showed cell ingrowth from the surface of gels toward their interior as deep as $\approx 2.5 \mathrm{~mm}$ from the surface (Figure 6D). The presence of cells on and within bisphosphonate-containing samples was less evident. Cytological imaging, combined with SEM and energy-dispersive X-ray (EDX) evaluations (Figure 6E-G), revealed the formation of a thick $(\approx 100 \mu \mathrm{m})$ layer of calcium phosphate on the surface of BPGel+BG(0.5) samples. As shown in Figure 6G, this newly formed layer was mainly composed of $\mathrm{Ca}$ (in red) and $\mathrm{P}$ (in green), which resembles the composition of the inorganic phase of bone, i.e., hydroxyapatite. Such a thick inorganic layer was not detected on the surface of the other samples that contained less BG particles.

\subsection{Osteocompatibility of Colloidal Gels}

Figure 7A shows the surgical procedure for implantation of colloidal gels into femoral condyles of osteoporotic rats. After eight weeks of implantation of the colloidal gels in femoral condyle defects, abundant bone formation was observed inside the original defect area for all colloidal gel compositions (Figure 7B-D), while no inflammatory response was observed for any of the implanted materials. The histological images showed that bone regeneration proceeded from the peripheral bone toward the center of the defect. Importantly, a large number of blood vessel-like structures could be observed throughout the defect area (Figure 7E,F), which seemed more apparent for the composite gels. Furthermore, as shown in Figure 7G, numerous cells were present within the bone-free central regions of the original defects.

Quantification of the amount of newly formed bone inside the original defect area indicated a high degree of bone formation for all the experimental groups (average values ranging from $26.0 \%$ to $31.8 \%$ ). The amounts of new bone formation were statistically similar for all groups (Figure 7H). Nevertheless, the experimental groups that 

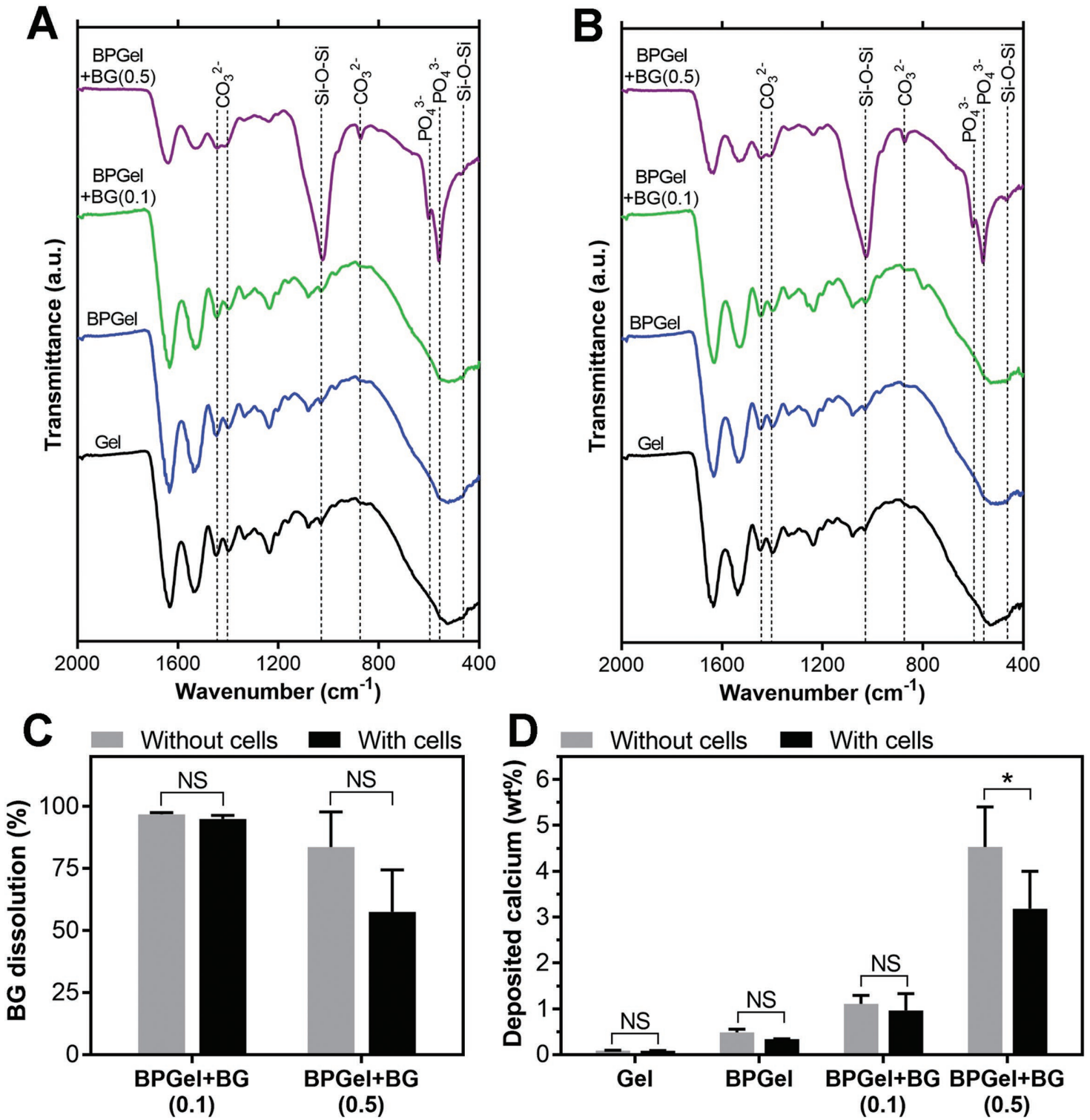

Figure 5. In vitro mineralization of colloidal gels. FTIR spectra of the freeze-dried colloidal gels after $30 \mathrm{~d}$ of incubation A) without or B) with cells. Estimated percentages of C) dissolved bioactive glass particles and D) deposited calcium within colloidal gels after $30 \mathrm{~d}$ of incubation with or without cells. All values in (C) and (D) are presented as average \pm standard deviation for $n=3$ per experimental condition. * and NS indicate $P \leq 0.05$ and not statistically significant, respectively.

contained bisphosphonate-functionalized gelatin formed significantly more bone than the bisphosphonate-free formulation in the $500 \mu \mathrm{m}$ area in vicinity to the defect (Figure 7I).

\section{Discussion}

Annually, around 9 million osteoporotic bone fractures occur worldwide, ${ }^{[19]}$ which means a new osteoporotic fracture takes place about every $4 \mathrm{~s}$, resulting in various types of bone defects. Consequently, biomaterials that can aid regeneration of bone defects for osteoporotic patients are highly demanded. Previous studies have demonstrated that colloidal gels can be developed which display that posse negligible cytotoxicity to human umbilical cord mesenchymal stem cells in vitro. ${ }^{[20]}$ Moreover, in vivo investigations have shown that these materials can be used as osteoconductive bone fillers with in vivo drug release ability. ${ }^{[21]}$ Although the assembly of biomaterials from colloidal particles was shown to be a promising strategy for the development of injectable and self-healing gels with tissue regenerative $e^{[8 a, b, 9 b, c, 20]}$ and drug release $e^{[9 a, 21,22]}$ capabilities, the potential of colloidal gel systems for regeneration of osteoporotic bone defects has never been explored before. Hence, the goal of this study was to develop injectable and self-healing composite colloidal gels that combine mechanical robustness with the capacity to regenerate osteoporotic bone through the concerted action of anabolic and anticatabolic stimuli. 

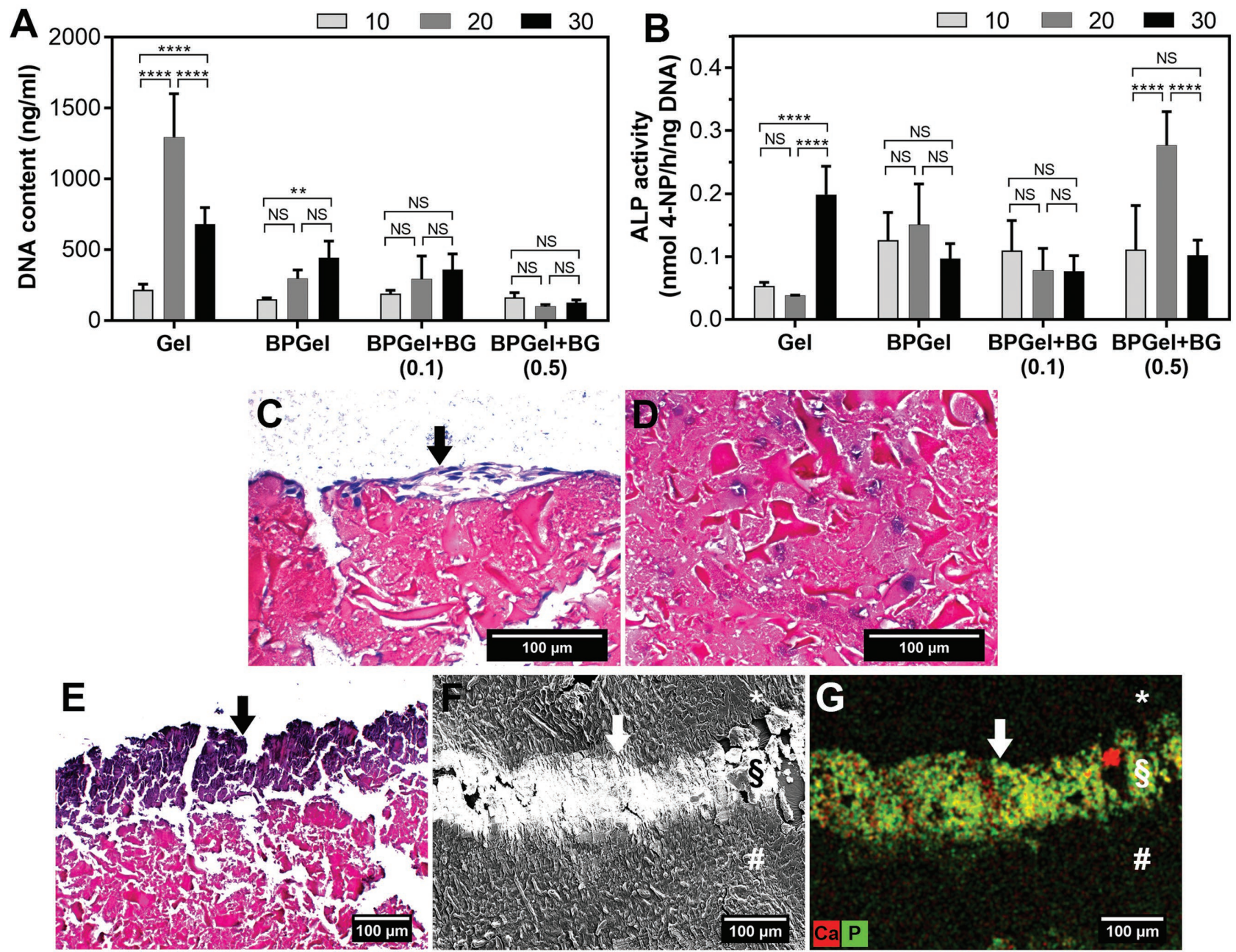

Figure 6. A) DNA content and B) ALP activity of colloidal gel samples during $30 \mathrm{~d}$ of cell culture experiments. All values in (A) and (B) are presented as average \pm standard deviation for $n=4$ per experimental condition. $* *$, $* k^{\prime} * *$, and NS indicate $P \leq 0.01, P \leq 0.0001$, and not statistically significant, respectively. Cross-sectional microscopy images of colloidal gels after $30 \mathrm{~d}$ of cell culture. Representative cytological images showing cells $\mathrm{C}$ ) on top and D) inside Gel samples. Representative E) cytological, F) SEM, and G) EDX mapping cross-sectional images showing extensive calcium phosphate formation on the top surface of BPGel+BG (0.5) samples. Arrows point to the top surface of samples. *, $\S$, and \# symbols in $(F)$ and $(G)$ indicate the embedding medium, the mineralized area, and the cross-section of samples.

The bulk mechanical properties of colloidal gels are determined by their microstructure, the mechanical properties of each colloidal particle, and the interactions between these particles within a colloidal gel network. ${ }^{[8 a, c]}$ We recently found ${ }^{[16]}$ that functionalization of hyaluronan macromers with calciumbinding bisphosphonate groups significantly enhances the binding affinity of this macromer toward calcium-containing BG particles. In addition, bisphosphonate functionalization of gelatin nanoparticles was recently shown ${ }^{[11]}$ to increase the interparticle adhesion between gelatin and hydroxyapatite particles. Based on these previous results, we hypothesized that strong adhesion forces could also be created between bisphosphonate-functionalized gelatin and BG particles. This hypothesis was indeed confirmed by means of AFM experiments using a colloidal probe technique (Figure 2A). Nevertheless, we also witnessed adhesive interactions between bisphosphonate-free gelatin and BG particles, which were similar to previous reports ${ }^{[23]}$ that demonstrated the existence of adhesive interactions between BG surfaces and fibrous collagen. Such adhesive interparticle interactions can arise from interparticle van der Waals and hydrophobic forces, as well as from local electrostatic attractions between the carboxyl or amine groups of gelatin and the cations $\left(\mathrm{Na}^{+}\right.$and $\left.\mathrm{Ca}^{2+}\right)$ or silanol groups of BG particles, respectively. ${ }^{[8 a, 24]}$ Nonetheless, upon bisphosphonate functionalization of gelatin nanoparticles, the interparticle adhesion forces significantly increased, most likely due to the formation of strong, but reversible, bonds between the bisphosphonate groups of gelatin nanoparticles and calcium ions at the surface of the BG particle. Since biomaterials are exposed to isotonic biological fluids when implanted in vivo, ${ }^{[25]}$ we also performed these AFM measurements in PBS solutions with a similar ionic strength as body fluids. Our results showed that the adhesion force values for both groups containing bisphosphonate-free and bisphosphonate-functionalized gelatin decreased when measured in PBS. This decrease is related to screening of interparticle electrostatic interactions at high 

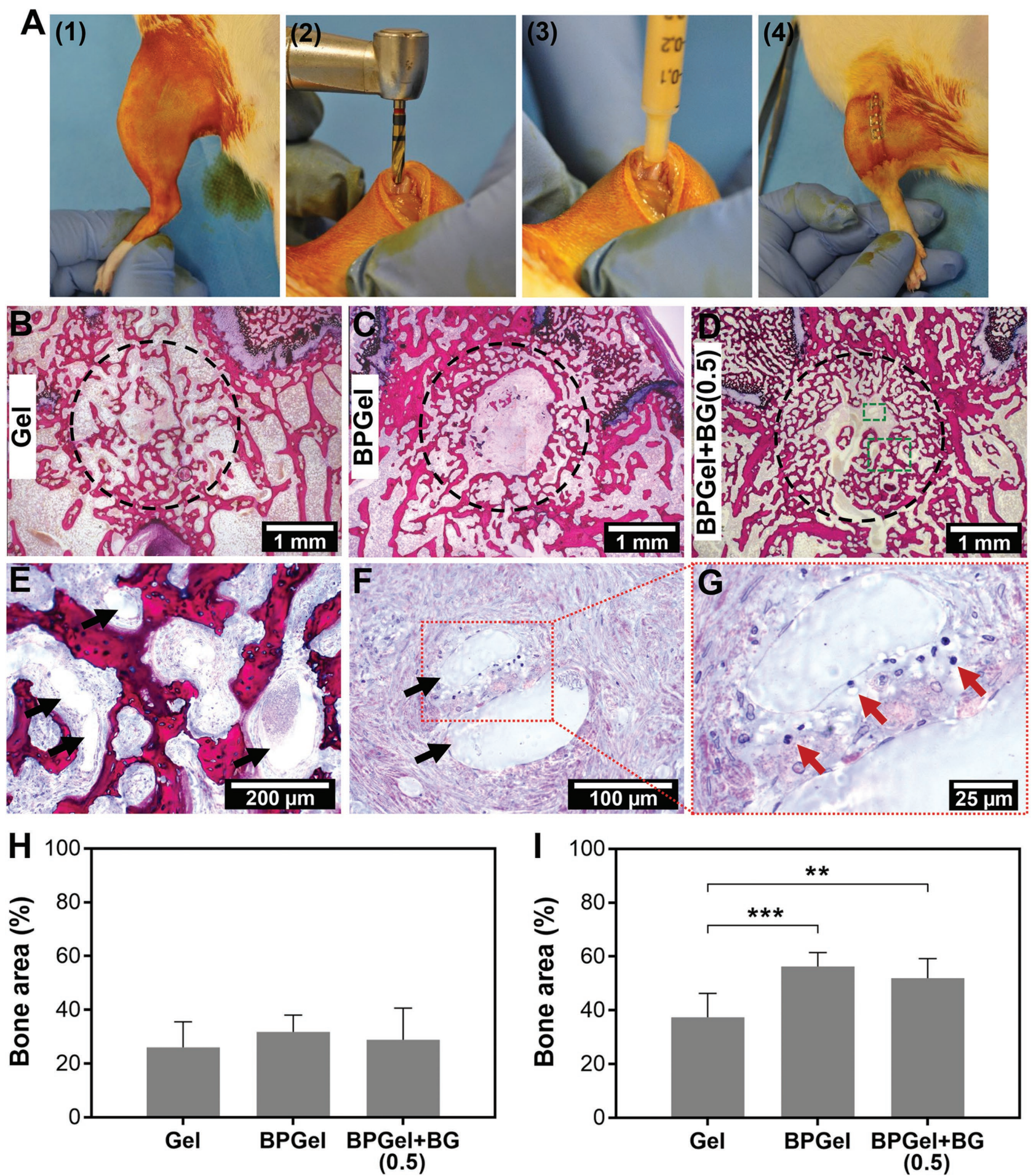

Figure 7. In vivo evaluation of colloidal gels. A) Digital photographs showing the surgical procedure for implantation of colloidal gels into femoral condyles of osteoporotic rats. B-D) Representative histological images of different experimental groups after eight weeks of implantation. The circles indicate the original defect areas. E,F) High magnification images of large and small rectangles in (D), respectively. G) High magnification image of the rectangle in (F). Black and red arrows indicate blood vessel-like structures and cells, respectively. Quantified bone area (\%) in $\mathrm{H}$ ) defect and I) peri-implantation regions. All values in $(\mathrm{H})$ and $(\mathrm{I})$ are presented as average \pm standard deviation for $n=8$ per experimental condition. $\mathrm{w}_{*}$ and $\mathrm{w}_{\mathrm{w}} \mathrm{k}$ represent $P \leq 0.01$ and $P \leq 0.001$, respectively.

ionic strengths. ${ }^{[26]}$ Nevertheless, even in PBS, adhesion forces between BG and gelatin particles were higher after bisphosphonate functionalization of gelatin particles. These findings stress that bisphosphonate-based interparticle bonds are more effective than electrostatic interactions at high ionic strengths such as isotonic body fluids. 
After preparation of colloidal gels using gelatin and BG particles, we studied the viscoelastic properties of these materials by means of rheology. Generally, the storage modulus of these composites increased with increasing BG content (Figure 3A). These results are in agreement with our previous observations, ${ }^{[8 \mathrm{a}, \mathrm{b}]}$ which confirmed that the combination of stiff inorganic particles with soft organic particles results in more elastic gels as compared to the use of organic particles only. ${ }^{[8 c, d]}$ However, as shown in Figure 3B, samples with BG/gelatin ratios higher than 1 displayed increased tan(delta) values, indicating that viscous behavior became more dominant at such high inorganic contents. Moreover, when immersed in water, these samples lost their integrity within a day (data not shown), indicating that the amount of gelatin particles was insufficient to establish a cohesive composite network. The effect of bisphosphonate functionalization of gelatin nanoparticles on the mechanical properties of colloidal gels was influenced by the composition and the particle volume fraction of these materials (Figure 3A,C). When the colloidal gels were entirely made of gelatin nanoparticles, bisphosphonate functionalization resulted in inferior mechanical properties (Figure 3A and Figure S3 (Supporting Information)), which can be attributed to repulsive interactions between negatively charged bisphosphonate groups present at the surface of gelatin nanoparticles. ${ }^{[1]} \mathrm{Nev}$ ertheless, bisphosphonate functionalization of gelatin particles increased the storage modulus of the formulations when BG particles were included in the colloidal systems. This effect was, however, not statistically significant at the highest BG contents, possibly due to the excess of BG particles within the colloidal gel networks at these compositions. Moreover, we found that by increasing the particle volume fraction, the influence of bisphosphonate functionalization on the viscoelastic properties of the composite gels gradually decreased. This decrease might be caused by the transition of the colloidal assembly from a fractal to a more compact morphology. ${ }^{[27]}$ Importantly, all colloidal gels with a BG/gelatin ratio $<1$ exhibited an intrinsic ability for selfhealing as evidenced by the immediate and substantial recovery of their storage modulus after destructive shearing (Figure 4). Based on these results, we produced composite gels using bisphosphonate-functionalized gelatin nanoparticles at BG/gelatin ratios of up to 0.5 for further in vitro and in vivo evaluation.

The evaluation of in vitro mineralization of these gels in cell culture media revealed that a minimum BG/gelatin ratio of 0.5 was essential to stimulate the formation of apatite within the matrix. Mineralization of these composite gels started within the first $10 \mathrm{~d}$ of incubation, and by day 30, the majority of BG particles were replaced by apatite (Figure 5 and Figure S2 (Supporting Information)). The presence of cells on these composites slightly decreased the extent of mineral deposition, possibly due to the formation of a cell layer limiting ion exchange between the gels and surrounding culture media. ${ }^{[15]}$ These results suggest that the mineralization of the composite colloidal gels mainly occurred through a passive route rather than an active route driven by cellular mineralization. ${ }^{[28]}$

Next, we studied the proliferation and osteoblastic activity of MC3T3 cells upon direct contact with the gels in the absence of osteogenic supplements (Figure 6). At $10 \mathrm{~d}$ of cell culture, the bisphosphonate functionalization of gelatin and incorporation of BG particles into the gels did not affect the proliferation and differentiation of cells. Nevertheless, at day 20, the presence of bisphosphonate in gels stimulated osteoblastic differentiation, which is in line with other reports showing that nitrogencontaining bisphosphonate drugs, such as alendronate, can stimulate osteogenic differentiation of cells. ${ }^{[29]}$ Most notably, for bisphosphonate-containing gels with the highest BG content $(\mathrm{BG} /$ gelatin ratio $=0.5)$, osteogenic differentiation of the cells continued to increase up to day 20 before it declined. It is known that during a normal osteogenic differentiation process, the ALP activity reaches a peak level upon osteoblast maturation, followed by a decline upon mineralization. ${ }^{[30]}$ Indeed, the cytological evaluation of these composite gels (BPGel+BG (0.5)) after $30 \mathrm{~d}$ of cell culture confirmed the formation of a thick layer of calcium phosphate on their surface (Figure 6), which is in agreement with the mineralization results discussed earlier. Nevertheless, it is important to point out that the in vitro osteogenic effects of BGs depend on the concentration of their dissolution products in cell culture medium. ${ }^{[31]}$ Consequently, these results cannot be translated to in vivo conditions, in view of the biologically more complex and perfused nature of animal studies. Therefore, to determine the in vivo capacity of the colloidal gels to regenerate defects in osteoporotic bone, we implanted the bioactive composite gels (BPGel+BG (0.5)) as well as bisphosphonate-containing (BPGel) and bisphosphonate-free (Gel) pure gelatin gels into bone defects created in femoral condyles of osteoporotic rats (Figure 7). After eight weeks, we observed abundant formation of vascularized bone inside the original defect area for all colloidal gel compositions. This vascularization was more apparent for the composite gels, most likely due to the angiogenic effect of BG particles..$^{[31,32]}$ Interestingly, similar to the cytological observations (Figure 6D), cells were observed in the central regions of the defects (Figure 7G). We attribute this observation to local adaptation of the gel network through repeated rupture and reformation of interparticle bonds, which allows cell migration into the gels without compromising the bulk integrity of the gels. ${ }^{[33]}$ This behavior differs from that of conventional covalently crosslinked hydrogels that do not allow cell migration due to their static nature. ${ }^{[34]}$

In view of the similarity regarding the amount of bone formation for the various experimental groups (Figure $7 \mathrm{H}$ ), it was concluded that the BG particles did not influence the amount of in vivo bone regeneration after eight weeks of implantation, even though the incorporation of BG particles was highly beneficial for the mechanical and in vitro biological properties of the colloidal gels. Regarding this matter, it is important to consider that our in vitro results revealed that the majority of BG particles of the composite gels were dissolved within a $30 \mathrm{~d}$ period. Accordingly, these in vitro findings could indicate that the amount of BG particles incorporated in the composite gels might not be sufficient to facilitate in vivo bone regeneration for an eight week period. Furthermore, the in vivo bioactivity of BG particles might be affected by the low concentration of serum calcium, ${ }^{[35]}$ caused by the low calcium diet of the rats. ${ }^{[36]}$ Nonetheless, it should be emphasized that we observed recently in a recent similar animal test (data not published) that femoral condyle defects in osteoporotic rats were regenerated for only $13.8 \pm 3.8 \%$ after 12 weeks (Figure S5, Supporting Information). This observation highlights the strong capacity of the colloidal gels to support the regeneration of osteoporotic bone. 
Finally, we investigated potential antiosteoporotic effects of our colloidal gels on the peridefect bone tissue by quantifying the bone area within a vicinity of $500 \mu \mathrm{m}$ surrounding the defects. These quantifications indicated a significantly enhanced bone regeneration in the surrounding tissue when the colloidal gels were functionalized with bisphosphonate molecules (Figure 7I). This antiosteoporotic effect can be ascribed to the release of bisphosphonate moieties from the colloidal gels, thereby attaining a therapeutically active bisphosphonate concentration within the peri-implantation region. These results are in agreement with previous reports by Karlsson et al. ${ }^{[3]}$ who showed that after eight weeks of implantation of alendronate-functionalized implants in rat tibia, released alendronate molecules remained confined within a vicinity of $500 \mu \mathrm{m}$ surrounding the implants. The highest bone density was observed at a distance of 10-100 $\mu \mathrm{m}$ from the surface of implants, possibly caused by optimal concentrations of released alendronate at this distance. Nevertheless, further investigations are required to determine the stability of the increased bone density caused by the local release of bisphosphonates, particularly in response to the process of bone remodeling over time. Furthermore, given the biological activity of different ions released from $\mathrm{BGs}^{[31]}$ it will be interesting to investigate in future studies the use of other BG compositions for the preparation of colloidal gels, notably those containing/releasing strontium ions which might act in synergy with bisphosphonates, ${ }^{[38]}$ leading to an improved treatment of osteoporotic bone defects.

\section{Conclusion}

We demonstrated successful regeneration of osteoporotic bone defects using bioactive composite colloidal gels made of bisphosphonate-functionalized gelatin and BG particles. We modified gelatin nanoparticles with bisphosphonate groups to enhance their affinity toward BG particles and exploit their antiosteoporotic activity to facilitate bone regeneration under osteoporotic conditions. This modification resulted in enhancement of the interparticle bonds between gelatin and BG building blocks, which improved the stiffness of specific colloidal gel compositions. By adjustment of the BG/gelatin ratio, composite gels were produced that combined mechanical robustness with self-healing ability. This self-healing capability allowed the recovery of mechanical properties of the gels after shearinduced destruction that can occur during injection of these materials through narrow syringes. The composite gels induced apatite formation and supported proliferation and differentiation of osteoblastic cells in vitro without requiring additional osteogenic supplements. In vivo evaluation of the regenerative capacity of the composite gels using an osteoporotic rat model demonstrated the ability of the composite gels to promote the formation of vascularized bone inside femoral condyle defects and to enhance the amount of bone formation around these defects. Overall, our results demonstrate that the self-healing composite colloidal gels developed in this study were mechanically robust and stimulated the regeneration of osteoporotic bone, which might open up new therapeutic opportunities for treatment of osteoporotic bone defects.

\section{Experimental Section}

For full experimental details, see the Supporting Information.

Synthesis and Functionalization of Gelatin Nanoparticles: Gelatin nanoparticles were synthesized by a two-step desolvation method using acetone and water. ${ }^{[8 a]}$ Bisphosphonate functionalization of nanoparticles was carried out according to the previous report. ${ }^{[1]}$

Atomic Force Microscopy: A colloidal probe AFM method was used to quantify the interactions between gelatin and $B G$ particles. The measurements were performed in MilliQ water $(\mathrm{pH}$ adjusted to 7 using $\mathrm{NaOH}$ solution) and PBS solutions at room temperature using a NanoWizard III AFM instrument (JPK Instruments AG, Germany) equipped with an inverted optical microscope (Olympus IX71, Germany). Force measurements were performed between a BG microsphere fixed on a cantilever and gelatin nanoparticles fixed on a glass slide.

Preparation of Colloidal Gels: To prepare the colloidal gels, different ratios of gelatin and BG powders were added in plastic tubes and thoroughly mixed using a spatula and vortexing. The particle volume fraction in a colloidal gel was defined as the total volume of solid BC particles and swollen gelatin nanoparticles divided by the total volume of the colloidal gel (i.e., particles plus free water). Depending on the desired particle volume fraction, a specific volume of MilliQ water was added to the powder. After addition of water, the tubes were subjected to $1 \mathrm{~min}$ of vortexing. Thereafter, the tubes were centrifuged for $1 \mathrm{~min}$ at $5000 \mathrm{rpm}$ to confine the colloidal gels at the bottom of the tubes.

Rheological Characterizations: Rheological properties of the colloidal gels were evaluated using an AR2000 Advanced Rheometer (TA Instruments) with a flat steel plate geometry (8 $\mathrm{mm}$ diameter) and gap distance of $500 \mu \mathrm{m}$ at $25^{\circ} \mathrm{C}$. Frequency sweep measurements $(0.1-10 \mathrm{~Hz})$ were carried out at a fixed strain of $0.5 \%$. Storage $(G)$ modulus, loss $\left(G^{\prime}\right)$ modulus, and tan(delta) of the colloidal samples were determined by performing a time sweep for $1 \mathrm{~min}$ at $0.5 \%$ strain and an oscillatory frequency of $1 \mathrm{~Hz}$. Yield stress of colloidal gels was determined by plotting the elastic stress $\left(G^{\prime}\right.$ multiplied by absolute strain) as function of strain amplitude $(0.5-1000 \%)$. Consequently, the peak stress value in the elastic stress-strain curve was interpreted as the yield stress of the colloidal gels. ${ }^{[39]}$ The self-healing ability of the gels was evaluated by measuring the recovery of $G^{\prime}$ after shear-induced gel network destruction (0.5-1000\% strain).

In Vitro Cell Culture and Mineralization Experiments: Osteoblast precursor cells (MC3T3 cell line; LGC Standards, Wesel, Germany) were used for in vitro studies. Colloidal gel samples were incubated in cell culture medium with or without cells for up to $30 \mathrm{~d}$. FTIR spectroscopy was used to monitor formation and growth of apatite minerals within the freeze-dried gels after each time point with or without cells. Inductively coupled plasma optical emission spectrometry was used for elemental analysis of freeze-dried gels. Cell proliferation was assessed by measuring the DNA content in each sample solution using a Quantifluor dsDNA System (Promega Corporation, USA). The differentiation of the cultured cells was quantified by assessing the ALP activity of the cells as an early marker for osteoblastic differentiation. The ALP activity was measured based on the ALP-mediated conversion of p-nitrophenyl phosphate to nitrophenol (see the Supporting Information). For cytological analyses, colloidal gels were fixated, dehydrated, and embedded in paraffin. Afterward, $6 \mu \mathrm{m}$ thick sections were cut perpendicular to the cell seeded surface using a standard microtome (RM 2165; Leica, Germany). For evaluation of the distribution of cells throughout the gels, the sections were stained with hematoxylin/eosin and assessed with optical microscopy. For evaluation of apatite formation throughout the gels, the sections were sputter-coated with a $10 \mathrm{~nm}$ thick chromium layer and assessed using SEM equipped with an EDX detector.

In Vivo Characterization of Colloidal Gels: A total of 16 male Wistar rats ( 12 weeks old, weight of $\approx 250 \mathrm{~g}$ ) was used for the implantation study. The study protocol was reviewed and approved by the Experimental Animal Committee of the Radboud University (RU-DEC 2015-0036-004) and carried out in accordance with national guidelines concerning care and use of laboratory animals. The rats underwent an orchidectomy (ORX), as described previously, ${ }^{[40]}$ and had free access to water and low-calcium 
pelleted chow $(0.01 \% \mathrm{Ca}$ and $0.77 \% \mathrm{P}$; ssniff Spezialdiäten $\mathrm{GmbH}$, Soest, Germany) to induce osteoporosis. Osteoporotic conditions were confirmed after six weeks using an in vivo microcomputed tomography imaging system (Inveon; Siemens Medical Solutions, Knoxville, TN) and the animals underwent surgical intervention for the implantation of colloidal gels in both femoral condyles in a randomized manner (Table S1, Supporting Information). In order to create bilateral frontal femoral condyle bone defects ( $n=8$ per experimental group), after careful exposure of the knee joint, a $1 \mathrm{~mm}$ pilot hole was drilled and the defect was gradually widened using different drills of increasing size using a surgical motor (Elcomed 100, W\&H Dentalwerk Burmoos, Austria) at low rotational drilling speed $(800 \mathrm{rpm})$ and continuous external cooling with saline, until a final cylindrical defect of $2.5 \mathrm{~mm}$ in diameter and $5 \mathrm{~mm}$ in depth was reached. Thereafter, the materials were implanted in the left or right femur of each animal under inhalation anesthesia (2\% Isoflurane by volume). After eight weeks, rats were euthanized by $\mathrm{CO}_{2}$ suffocation, after which the femoral condyles were dissected, cleaned from adhering tissues, and then immediately fixed in neutral buffered formaldehyde for $48 \mathrm{~h}$. After fixation, samples were kept in 70\% ethanol, dehydrated in graded series of ethanol solutions (70-100\%), and embedded in poly (methylmethacrylate). Following polymerization, non-decalcified $\approx 10 \mu \mathrm{m}$ thick longitudinal sections were made crosssectional perpendicular on the longitudinal axis of the implanted material (at least three sections per specimen) using a modified sawing microtome technique ${ }^{[4]]}$ and stained with methylene blue and basic fuchsin. Histomorphometrical analysis was carried out using Image) software and was based on the combination of histological staining and tissue morphology.

\section{Supporting Information}

Supporting Information is available from the Wiley Online Library or from the author.

\section{Acknowledgements}

M.D. would like to thank Yang Zhang, Monique Kersten-Niessen, and Natasja van Dijk for their valuable suggestions and assistance with the experiments. M.D. would also like to thank Prof. Peter Fratzl and to acknowledge the travel award from the ICSHM2013 conference for supporting his research stay at the MPI-Potsdam. XL Sci-Tech, Inc. is acknowledged for providing the bioactive glass microspheres. This study was funded by the Netherlands Enterprise Agency through Project No. SHM012014 in the theme IOP Self Healing Materials.

\section{Conflict of Interest}

The authors declare no conflict of interest.

\section{Keywords}

biomedical applications, colloids, composite materials, hydrogels, self-healing

Received: June 23, 2017

Revised: August 14, 2017

Published online: October 16, 2017

[1] H. S. Alghamdi, R. Bosco, J. J. J. P. van den Beucken, X. F. Walboomers, J. A. Jansen, Biomaterials 2013, 34, 3747.
[2] H. C. Pape, A. Evans, P. Kobbe, J. Orthop. Trauma 2010, 24, S36.

[3] J. W. M. Vehof, P. H. M. Spauwen, J. A. Jansen, Biomaterials 2000, 21, 2003.

[4] J. D. Kretlow, A. G. Mikos, AIChE J. 2008, 54, 3048.

[5] a) K. Rezwan, Q. Z. Chen, J. J. Blaker, A. R. Boccaccini, Biomaterials 2006, 27, 3413; b) H. Shin, S. Jo, A. G. Mikos, Biomaterials 2003, $24,4353$.

[6] J. D. Kretlow, S. Young, L. Klouda, M. Wong, A. G. Mikos, Adv. Mater. 2009, 21, 3368.

[7] S. Utech, A. R. Boccaccini, J. Mater. Sci. 2016, 51, 271.

[8] a) M. Diba, H. Wang, T. E. Kodger, S. Parsa, S. C. G. Leeuwenburgh, Adv. Mater. 2017, 29, 1604672; b) H. Wang, M. Bongio, K. Farbod, A. W. G. Nijhuis, J. van den Beucken, O. C. Boerman, J. C. M. van Hest, Y. Li, J. A. Jansen, S. C. G. Leeuwenburgh, Acta Biomater. 2014, 10, 508; c) H. Wang, M. B. Hansen, D. W. P. M. Löwik, J. C. M. van Hest, Y. Li, J. A. Jansen, S. C. G. Leeuwenburgh, Adv. Mater. 2011, 23, H119; d) Q. Wang, L. Wang, M. S. Detamore, C. Berkland, Adv. Mater. 2008, 20, 236.

[9] a) J. Song, J. C. E. Odekerken, D. W. P. M. Löwik, P. M. López-Pérez, T. J. M. Welting, F. Yang, J. A. Jansen, S. C. G. Leeuwenburgh, Macromol. Biosci. 2015, 15, 901; b) J. van der Stok, H. Wang, S. Amin Yavari, M. Siebelt, M. Sandker, J. H. Waarsing, J. A. N. Verhaar, H. Jahr, A. A. Zadpoor, S. C. G. Leeuwenburgh, H. Weinans, Tissue Eng., Part A 2013, 19, 2605; c) H. Wang, Q. Zou, O. C. Boerman, A. W. G. Nijhuis, J. A. Jansen, Y. Li, S. C. G. Leeuwenburgh, J. Controlled Release 2013, 166, 172; d) H. Wang, O. C. Boerman, K. Sariibrahimoglu, Y. Li, J. A. Jansen, S. C. G. Leeuwenburgh, Biomaterials 2012, 33, 8695.

[10] M. V. Priya, A. Sivshanmugam, A. R. Boccaccini, O. M. Goudouri, W. Sun, N. Hwang, S. Deepthi, S. V. Nair, R. Jayakumar, Biomed. Mater. 2016, 11, 035017.

[11] K. Farbod, M. Diba, T. Zinkevich, S. Schmidt, M. J. Harrington, A. P. M. Kentgens, S. C. G. Leeuwenburgh, Macromol. Biosci. 2016 16, 717.

[12] K. Farbod, A. Curci, M. Diba, T. Zinkevich, A. P. M. Kentgens, M. Iafisco, N. Margiotta, S. C. G. Leeuwenburgh, RSC Adv. 2016, 6, 113025.

[13] R. Schrieber, H. Gareis, Gelatine Handbook: Theory and Industrial Practice, John Wiley \& Sons, Hoboken, NJ, 2007.

[14] S.-C. Wu, W.-H. Chang, G.-C. Dong, K.-Y. Chen, Y.-S. Chen, C.-H. Yao, J. Bioact. Compat. Polym. 2011, 26, 565.

[15] J. R. Jones, Acta Biomater. 2013, 9, 4457.

[16] M. Diba, J. An, S. Schmidt, M. Hembury, D. Ossipov, A. R. Boccaccini, S. C. G. Leeuwenburgh, Macromol. Rapid Commun. 2016, 37, 1952.

[17] H. Fleisch, Endocr. Rev. 1998, 19, 80.

[18] M. Mačković, A. Hoppe, R. Detsch, D. Mohn, W. J. Stark, E. Spiecker, A. R. Boccaccini, J. Nanopart. Res. 2012, 14, 966.

[19] O. Johnell, J. A. Kanis, Osteoporosis Int. 2006, 17, 1726

[20] a) Q. Wang, Z. Gu, S. Jamal, M. S. Detamore, C. Berkland, Tissue Eng., Part A 2013, 19, 2586; b) Q. Wang, S. Jamal, M. S. Detamore, C. Berkland, J. Biomed. Mater. Res., Part A 2011, 96A, 520.

[21] Q. Wang, J. Wang, Q. Lu, M. S. Detamore, C. Berkland, Biomaterials 2010, 31, 4980.

[22] J. Di, J. Yu, Q. Wang, S. Yao, D. Suo, Y. Ye, M. Pless, Y. Zhu, Y. Jing, Z. Gu, Nano Res. 2017, 10, 1393.

[23] a) R. Oréfice, L. Hench, A. Brennan, J. Biomed. Mater. Res., Part A 2009, 90A, 114; b) L. L. Hench, D. Greenspan, J. Aust. Ceram. Soc. 2013, 49, 1

[24] a) K. Magyari, L. Baia, O. Popescu, S. Simon, V. Simon, Vib. Spectrosc. 2012, 62, 172; b) S. Lin, W. Van den Bergh, S. Baker, J. R. Jones, Acta Biomater. 2011, 7, 3606.

[25] T. Kokubo, H. Takadama, Biomaterials 2006, 27, 2907. 
[26] a) R. Perez-Jimenez, R. Godoy-Ruiz, B. Ibarra-Molero, J. M. Sanchez-Ruiz, Biophys. J. 2004, 86, 2414; b) G. Trefalt, T. Palberg, M. Borkovec, Curr. Opin. Colloid Interface Sci. 2017, $27,9$.

[27] Z. Shao, A. S. Negi, C. O. Osuji, Soft Matter 2013, 9, 5492.

[28] T. Kirsch, Connect. Tissue Res. 2012, 53, 438.

[29] a) E. Boanini, P. Torricelli, M. Gazzano, R. Giardino, A. Bigi, Biomaterials 2008, 29, 790; b) D. Zheng, K. G. Neoh, E.-T. Kang, J. Colloid Interface Sci. 2017, 487, 1; c) F. P. Koch, C. Merkel, B. Al-Nawas, R. Smeets, T. Ziebart, C. Walter, W. Wagner, J. Craniomaxillofac. Surg. 2011, 39, 562.

[30] a) J. E. Aubin, Rev. Endocr. Metab. Disord. 2001, 2, 81; b) R. A. Thibault, L. Scott Baggett, A. G. Mikos, F. K. Kasper, Tissue Eng., Part A 2009, 16, 431.

[31] A. Hoppe, N. S. Güldal, A. R. Boccaccini, Biomaterials 2011, 32, 2757.

[32] A. Arkudas, A. Balzer, G. Buehrer, I. Arnold, A. Hoppe, R. Detsch, P. Newby, T. Fey, P. Greil, R. E. Horch, A. R. Boccaccini, U. Kneser, Tissue Eng., Part C 2012, 19, 479.

[33] H. Wang, S. C. Heilshorn, Adv. Mater. 2015, 27, 3717.
[34] C. M. Kirschner, K. S. Anseth, Acta Mater. 2013, 61, 931.

[35] M. R. Filgueiras, G. La Torre, L. L. Hench, J. Biomed. Mater. Res. 1993, 27, 445.

[36] I. Wolinsky, K. Guggenheim, Comp. Biochem. Physiol., Part A: Mol. Integr. Physiol. 1974, 49, 183.

[37] a) J. Karlsson, A. Martinelli, H. M. Fathali, J. Bielecki, M. Andersson, J. Biomed. Mater. Res., Part A 2016, 104, 620; b) J. Karlsson, N. Harmankaya, S. Allard, A. Palmquist, M. Halvarsson, P. Tengvall, M. Andersson, J. Mater. Sci.: Mater. Med. 2015, 26, 11.

[38] a) E. Boanini, P. Torricelli, M. Gazzano, E. Della Bella, M. Fini, A. Bigi, Biomaterials 2014, 35, 5619; b) B. Busse, B. Jobke, M. Hahn, M. Priemel, M. Niecke, S. Seitz, J. Zustin, J. Semler, M. Amling, Acta Biomater. 2010, 6, 4513.

[39] M. C. Yang, L. E. Scriven, C. W. Macosko, J. Rheol. 1986, 30, 1015.

[40] H. S. Alghamdi, J. J. J. P. van den Beucken, J. A. Jansen, Tissue Eng., Part C 2013, 20, 493.

[41] H. van der Lubbe, C. Klein, K. De Groot, Stain Technol. 1988, 63, 171. 